Article

\title{
A Simplified Method of Synthesis to Obtain Zwitterionic Cellulose under Mild Conditions with Active Ionic Moieties
}

\author{
Nadia B. Haro-Mares, Juan C. Meza-Contreras, Fernando A. López-Dellamary Toral, \\ Ricardo González-Cruz, José A. Silva-Guzmán and Ricardo Manríquez-González * \\ Department of Wood, Cellulose and Paper, CUCEI, University of Guadalajara, \\ 45020 Guadalajara, Jalisco, Mexico; aradia_b@hotmail.com (N.B.H.-M.); \\ jcmezac@academicos.udg.mx (J.C.M.-C.); ferdellam@gmail.com (F.A.L.-D.T.); \\ ricardo.gonzalezc@academicos.udg.mx (R.G.-C.); jasilva@dmcyp.cucei.udg.mx (J.A.S.-G.) \\ * Correspondence: rmanri@dmcyp.cucei.udg.mx or rmanri@gmail.com; Tel.: +52-33-3682-0110
}

Academic Editor: Gregory Chatel

Received: 12 June 2020; Accepted: 2 July 2020; Published: 5 July 2020

\begin{abstract}
A simplified procedure to synthesize zwitterionic cellulose by means of N-protected aspartic anhydride under mild conditions was developed. The preparation of modified cellulose samples was carried out under heterogeneous, aqueous conditions by reacting $\mathrm{NH}_{4} \mathrm{OH}$-activated cellulose with aspartic anhydrides N-protected with trifluoroacetyl (TFAc) and carbobenzyloxy (Cbz). Modified cellulose samples Cel-Asp-N-TFAc and Cel-Asp-N-Cbz were characterized by Fourier Transform Infrared (FTIR) and ${ }^{13} \mathrm{C}$ solid state Nuclear Magnetic Resonance (NMR) spectroscopy. The functionalization degree of each cellulose sample was determined by the ${ }^{13} \mathrm{C}$ NMR signal integration values corresponding to the cellulose $\mathrm{C} 1$ vs. the $\mathrm{C} \alpha$ of the aspartate residue and corroborated by elemental analysis. In agreement, both analytical methods averaged a grafting degree of $20 \%$ for Cel-Asp-N-TFAc and $16 \%$ for Cel-Asp-N-Cbz. Conveniently, Cel-Asp-N-TFAc was concomitantly partially N-deprotected (65\%) as determined by the ninhydrin method. The zwitterion character of this sample was confirmed by a potentiometric titration curve and the availability of these amino acid residues on the cellulose was inspected by adsorption kinetics method with a $100 \mathrm{mg} \mathrm{L}^{-1}$ cotton blue dye solution. In addition, the synthesis reported in the present work involves environmentally related advantages over previous methodologies developed in our group concerning to zwitterionic cellulose preparation.
\end{abstract}

Keywords: zwitterionic cellulose; N-protected aspartic anhydride; functionalization degree; amino acid deprotection; mild conditions; ionic moieties

\section{Introduction}

Cellulose is the most abundant structural component in plants, i.e., $10 \%$ to $20 \%$ of leaf dry weight, almost $50 \%$ in wood and bark and $90 \%$ in cotton linters. It is also one of the most abundant natural polymers in the world, easy to get, economically profitable, biodegradable, renewable and has attractive mechanical, biological and chemical properties [1]. From a chemical point of view, cellulose is a polysaccharide composed of linear chains of anhydroglucose repeating units (AGU) linked together through $\beta 1 \rightarrow 4$ glycosidic bonds. As a polysaccharide, hydroxyls $(-\mathrm{OH})$ are the main functional group, which are suitable for chemical modification by means of substitution, addition and oxidation reactions [2-4]. Many of these chemical modifications take place in homogenous reactions where cellulose is solubilized under different chemical conditions in order to increase the degree of substitution and improve the distribution of the chemical groups along the polymer $[5,6]$. However, such processes involve large amounts of organic solvents, both during the reaction and for 
the purification of the products. Moreover, most of the solvents and chemicals typically used are toxic and harmful to the environment, i.e., $\mathrm{CS}_{2}$, dimethylacetamide, lithium chloride, urea, concentrated acids and alkalis among others [7-10]. On the other hand, chemical modification of cellulose under heterogeneous reactions has been another possibility to introduce different chemical functionality onto the surface. This grafting procedure takes place when cellulose stays insoluble during the modification process. Although the degree of substitution in the polysaccharide is lower in comparison with the homogenous reaction, the amount of harmful waste produced by heterogeneous reactions can be also lower or in some cases solvent free [11]. Thus, both procedures present advantages and disadvantages in relation to achieving better polymer properties or promoting environmentally friendly procedures.

An area of interest in cellulose modification research has been to confer, for different purposes, ionic characteristics to this polysaccharide, by means of introducing cationic or anionic moieties [12-15]. On the other hand, some reports have explored the modification of cellulose using zwitterionic groups, as well as its potential uses and applications [16-19]. In this regard, investigations by some members of our group have previously proved that covalently attaching amino acids (with equimolar amount of negative and positive sites) on cellulose fibers contributes in increasing the interfiber bonding strength around $35 \%$ in wet paper sheets [20]. Accordingly, solid state of ${ }^{13} \mathrm{C}$ and ${ }^{15} \mathrm{~N}$ Nuclear Magnetic Resonance (NMR) spectroscopy has been employed for the characterization of the zwitterionic cellulose and determining how the zwitterionic groups are arranged. Furthermore, zwitterionic interactions between amino acid residues on cellulose fibers were also investigated with the measurement of internuclear ${ }^{13} \mathrm{C}-{ }^{15} \mathrm{~N}$ distances by solid state NMR employing Rotational-Echo Double-Resonance (REDOR) experiment [21]. Consequently, these results motivated us to inquire into possible applications, such as adsorption and separation systems for ions (i.e., heavy metal uptake in polluted water and ionic chromatography), new adhesives, and enzyme and cell immobilization for use in biocatalysis (recoverable catalytic systems). However, the preparation method that we first developed for this zwitterionic cellulose [22] is not environmentally friendly. Here, cupric ion was used as an amino acid protecting group during the synthesis keeping the temperature at $0{ }^{\circ} \mathrm{C}$, then it was removed at the end by ethylenediaminetetraacetic acid (EDTA) complexation, generating EDTA-Cu hazardous wastes [10]. From an environmental point of view, our main challenge for the zwitterionic modification of cellulose is to find new procedures to get an appropriate functionalization degree using less demanding and polluting conditions. Recently, we demonstrated the possibility of uptake Congo red dye up to $541.8 \mathrm{mg} \mathrm{g}^{-1}$ by means of $16.6 \%$ of zwitterionic modification of cellulose with Trimethoxysilylpropyldiethylenetriamine and1,4 butane sultone (Cel-TAS) under a heterogeneous reaction [23]. However, the preparation of the zwitterionic precursor (TAS) was made refluxing the reaction mixture in tetrahydrofuran (THF), which implies temperature and a hazardous solvent.

One approach for cellulose modification that matches this challenge is using activated dicarboxylic amino acid anhydrides as modifiers of cellulose under a less aggressive reaction medium. However, the classical methods for modifying polysaccharides with anhydrides are catalyzed with acetic acid at $85^{\circ} \mathrm{C}$ [24] or by aqueous $\mathrm{NaOH}$ [25], which can promote either decomposition or depolymerization of cellulose. There have been only few previous reports describing the use of heterogeneous methods for modifying cellulose with anhydrides in less alkaline aqueous conditions [26,27]. In one of them, cellulose was modified by esterification with succinic anhydride and $\mathrm{NH}_{4} \mathrm{OH}$ solution, employing thermal treatments from 160 to $210{ }^{\circ} \mathrm{C}$. Another report involved maleic anhydride in the presence of ammonia (both gaseous $\mathrm{NH}_{3}$ and $\mathrm{NH}_{4} \mathrm{OH}$ solution) at room temperature and with reaction times from 1 to $48 \mathrm{~h}$. The result of this work was the formation of cellulose aspartate with a degree of substitution (DS) from 0.001 to 3.0. The authors suggest that the aspartate was also formed in the same esterification process, due to the ammonia addition onto the double bound of the maleic anhydride.

In addition to the latter, this aspartate modification of cellulose seems to be difficult to control due to cross-linking of the polysaccharide through two aspartate residues. Although those methods are environmentally safe for the chemical modification of cellulose, the first involved high temperatures (energy consumption), which can also degrade the polysaccharide matrix. In the second process, 
reaction times could be too long (up to $48 \mathrm{~h}$ ), and the amino acid functionality of the aspartate would not always be available, since the amino group could be involved in the cross-linking. Therefore, from our particular point of view, these problems could be avoided by using N-protected amino acid anhydrides, in aqueous ammonia under mild conditions and moderately short reaction times $\left(60^{\circ} \mathrm{C} / 2\right.$ h), followed by protecting group cleavage. This main challenge can be achieved introducing a cellulose pretreatment step that could promote better conditions to the amino acids grafting process [28].

Accordingly, in the present work we show a simplified procedure for preparing zwitterionic cellulose, by reacting $\mathrm{N}$-protected aspartic anhydrides with cellulose, which has been previously activated with a minimal amount of $\mathrm{NH}_{4} \mathrm{OH}$. All steps are taking place under mild conditions and involve less polluting chemical procedures. The structural characterization of the resulting zwitterionic celluloses was carried out by Fourier Transform Infrared with Attenuated Total Reflectance (FTIR-ATR) and ${ }^{13} \mathrm{C}$ solid state NMR. The degree of functionalization of the samples was first estimated by ${ }^{13} \mathrm{C}$ NMR and corroborated by elemental analysis. Ninhydrin assay [22] was employed to investigate whether or not the reaction conditions also promoted concomitant $\mathrm{N}$-deprotection in the aspartate graft. Finally, the zwitterionic character and the availability of the amino acid residues in cellulose were evaluated by a potentiometric titration curve and dye adsorption test.

\section{Results and Discussion}

\subsection{Spectroscopic Characterization of the Cel-Asp Samples}

Figure 1 shows the FTIR spectra of cellulose (a) and cellulose modified with N-TrifluoroacetylL-aspartic anhydride (Cel-Asp-N-TFAc) (spectrum b). In both spectra, typical signals corresponding to the cellulose chemical groups are observed at 3334 and 3276, 2900 and 1053 and $1023 \mathrm{~cm}^{-1}$ which are due to $\mathrm{O}-\mathrm{H}, \mathrm{C}-\mathrm{H}$ and $\mathrm{C}-\mathrm{O}$ stretching vibrations, respectively $[29,30]$. In the sample Cel-Asp-N-TFAc, there are some spectral differences compared to untreated cellulose which are shown in the highlighted inset between 1800 and $1500 \mathrm{~cm}^{-1}$. Cellulose spectrum (a) presented the classical band at $1640 \mathrm{~cm}^{-1}$ assigned to adsorbed water. In spectrum $\mathbf{b}$, new bands confirmed the presence of the aspartic ester grafted onto cellulose. The signal located at $1712 \mathrm{~cm}^{-1}$ is assigned to ester carbonyl groups and the small band at $1673 \mathrm{~cm}^{-1}$ could be attributed to $\mathrm{C}=\mathrm{O}$ stretching of the trifluoroacetyl N-protecting group. The last broad and a strong band at $1591 \mathrm{~cm}^{-1}$ could be originated by carboxylate groups $\left(\mathrm{R}-\mathrm{COO}^{-}\right)$as well as $-\mathrm{N}-\mathrm{H}^{+}$[31-33] indicating the presence of the zwitterionic form of the amino acid. On other hand, the signal attributed to the N-H bending vibration of NH-TFAc is overlapped by the carbonyl signal at $1673 \mathrm{~cm}^{-1}$.

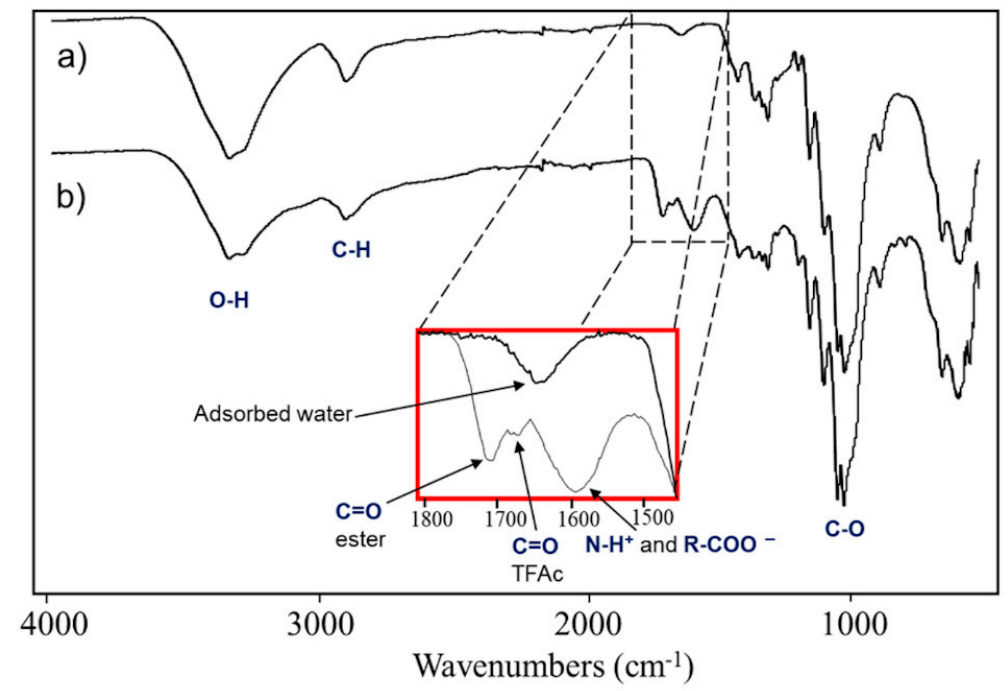

Figure 1. Fourier Transform Infrared spectra of: (a) Cellulose sample and (b) cellulose modified with $\mathrm{N}$-trifluoroacetyl-L-aspartic anhydride (Cel-Asp-N-TFAc). 
FTIR spectra of cellulose and cellulose modified with N-Carbobenzyloxy-L-aspartic anhydride (Cel-Asp-N-Cbz) are depicted in Figure 2a,b, respectively. Once again, the presence of the cellulose matrix is observed in both samples by the classical $\mathrm{O}-\mathrm{H}$, aliphatic $\mathrm{C}-\mathrm{H}$ and $\mathrm{C}-\mathrm{O}$ signals pattern as was described previously. A carbonyl signal located at $1700 \mathrm{~cm}^{-1}$ is observed clearly in the inset region (1800-1500 $\mathrm{cm}^{-1}$ ) of spectrum $\mathbf{b}$, which could arise from the aspartic ester group on cellulose, as well as the urethane moiety of the N-protecting group Cbz. Furthermore, bands at 1588 and $1521 \mathrm{~cm}^{-1} \mathrm{can}^{-}$ be attributed to either carboxylate groups from the aspartic acid or to aromatic rings from $\mathrm{Cbz}$.

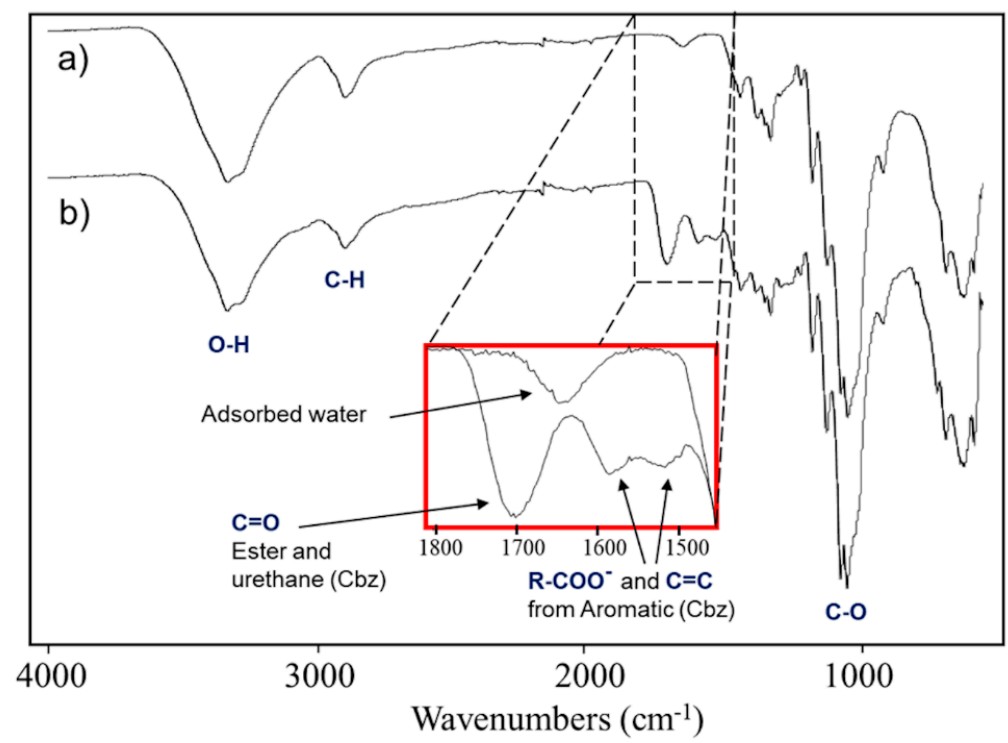

Figure 2. FTIR spectra of: (a) cellulose sample and (b) cellulose modified with N-carbobenzyloxy-Laspartic anhydride (Cel-Asp-N-Cbz).

Modified cellulose samples were also analyzed by ${ }^{13} \mathrm{C}$ solid state NMR. These spectra are shown in Figure 3 for Cel-Asp-N-TFAc and Figure 4 for Cel-Asp-N-Cbz. ${ }^{13} \mathrm{C}$ CPMAS NMR spectra of modified celluloses showed the carbon signals pattern of the cellulose matrix anhydroglucose repeating units (C1 to C6), in the chemical shift range from 60 to 110 ppm [34]. Furthermore, the characteristic signals profile remains for cellulose I (with the crystalline and amorphous components defined in C4 and C6) suggesting that neither the cellulose alkaline pretreatment nor the modification process significantly affects the cellulose crystalline structure (less than 10\%) [23,35] as can be observed in Figures 3 and 4. In the spectrum of the Cel-Asp-N-TFAc sample, signals corresponding to the aspartic group grafted on cellulose at 176, 53 and 36 ppm are observed. A broad signal at $176 \mathrm{ppm}$ is attributed to the carbonyl carbons from both the ester and carboxylate moieties and the signals at 53 and 37 ppm are assigned respectively to the $\alpha$ and $\beta$ carbons of the amino acid [36]. Surprisingly, the small size of signals at 116 and 158 ppm may be attributed to the loss of some Trifluoroacetyl N-protecting group. This fact suggests that unexpected spontaneous deprotection is taking place during the synthesis procedure. In contrast, Figure 4 shows that the carbon signals corresponding to the N-protecting group $\mathrm{Cbz}$ in the sample Cel-Asp-N-Cbz, are still clearly observed at 129 and 137 ppm (the aromatic ring carbons). In addition, the carbonyl from the urethane moiety at $157 \mathrm{ppm}$ is present as well. This confirmed that the $\mathrm{Cbz}$ group was not cleaved during cellulose modification, while TFAc was extensively removed. Other conclusions can be drawn from the signals corresponding to $\alpha$ and $\beta$ carbons in the amino acid backbone, located at 52 and 39 ppm, respectively. This last signal, assigned to the beta carbon of the aspartate, seems to be shifted up-field around 2 ppm in sample Cel-Asp-N-TFAc (Figure 3). This fact may indicate differences in amino acid orientation or, in other words, which carbonyl from the aspartic anhydride is connected to cellulose. Since $\mathrm{Cbz}$ remains in the modified cellulose Cel-Asp-N-Cbz and this protecting group is bulkier than TFAc, we can picture the scenario where the amino acid (aspartate) is oriented alpha, and the carbonyl carbon $4^{\prime}$ is attached to cellulose as shown in the Figure 4 . On the 
other hand, the amino acid in the Cel-Asp-N-TFAc would be connected to cellulose through carbon $\mathbf{1}^{\prime}$ following a beta orientation as isoaspartate (see Figure 3). These changes in the amino acid orientation attached on cellulose can be attributed to the strong electron withdrawing effect on carbon $\mathbf{1}^{\prime}$ of the aspartic anhydride due to the TFAc $\mathrm{N}$-protecting group. Therefore, carbon $\mathbf{1}^{\prime}$ is more electrophilic when TFAc is used, in comparison with aspartic anhydride with $\mathrm{N}-\mathrm{Cbz}$, due to the electron withdrawing inductive effect from the three fluorine atoms alpha to the carbonyl promoting a regioselective reaction, as was recently reported by Sahoo et al. [37]. Additionally, the steric effect of TFAc is smaller than Cbz.

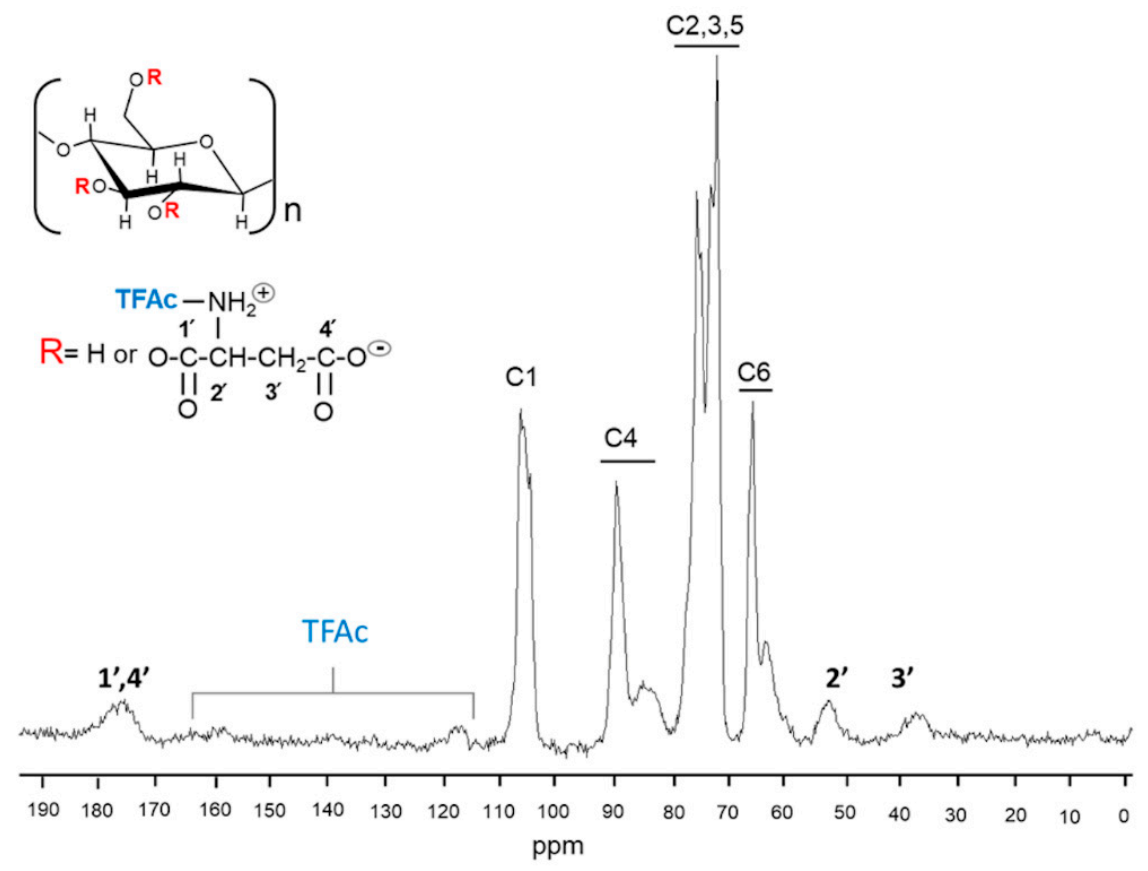

Figure 3. Carbon 13 by cross polarization magic angle spinning $\left({ }^{13} \mathrm{CCPMAS}\right)$ Nuclear Magnetic Resonance (NMR) spectrum of cellulose modified with N-trifluoroacetyl-L-aspartic anhydride (Cel-Asp-N-TFAc).

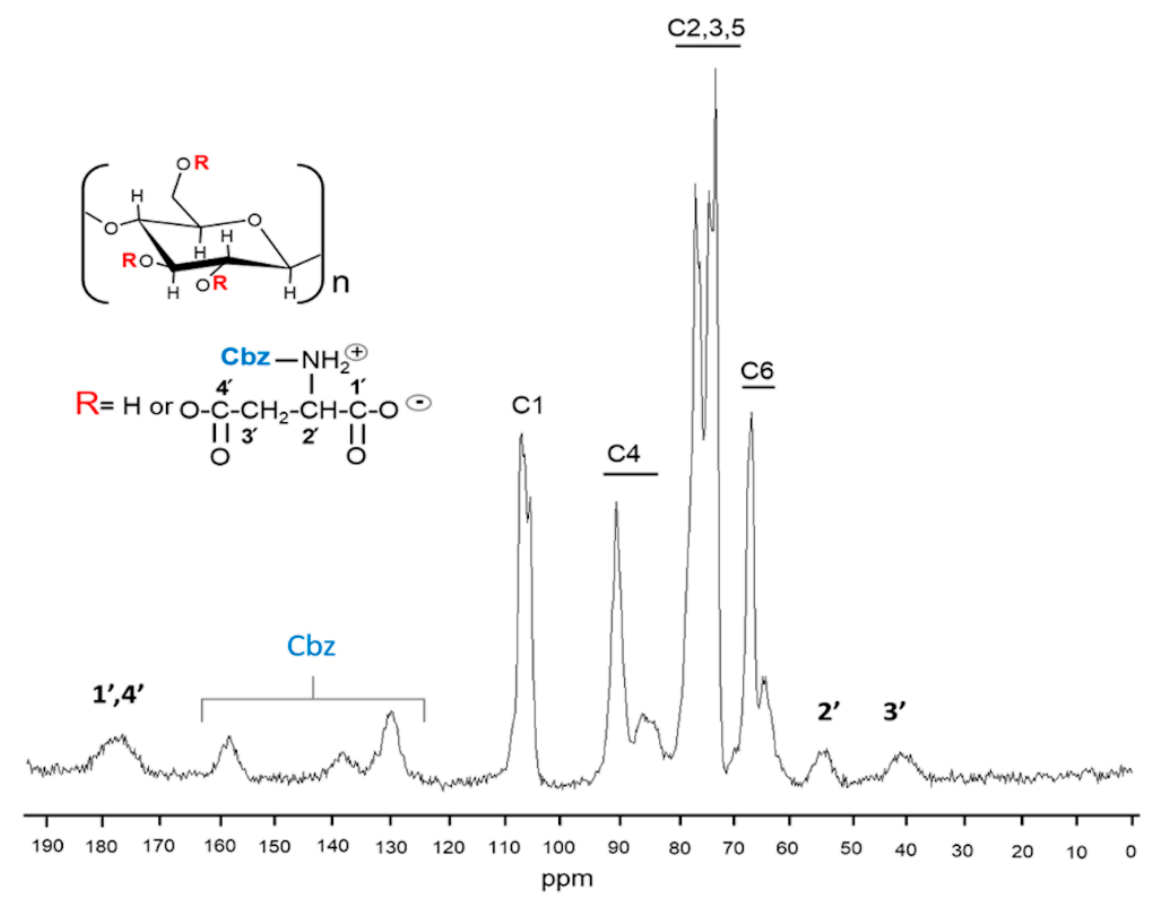

Figure 4. ${ }^{13} \mathrm{C}$ CPMAS NMR spectrum of cellulose modified with N-carbobenzyloxy-L-aspartic anhydride (Cel-Asp-N-Cbz). 


\subsection{Evaluation of the Functionalization and Deprotection Degrees in Aspartate-Modified Celluloses}

Table 1 shows the solid state ${ }^{13} \mathrm{C}$ NMR signal integration and Elemental Analysis results, for the grafting degree (GD) in the modified celluloses, using aspartic anhydride with TFAc or Cbz N-protecting groups. When ${ }^{13} \mathrm{C}$ NMR was used, the calculations were based on the ratio between the integral values of the cellulose $\mathrm{C} 1$ signal and the aspartate alpha carbon $(\mathrm{C} \alpha)$ in each cellulose sample (Cel-Asp-N-TFAc and Cel-Asp-N-Cbz) (see Figures S1 and S2 in the Supporting Material Section). The percentage of functionalization was also determined by fixing the $\mathrm{C} 1$ signal area of each sample as $100 \%$. From this calculation, the Cel-Asp-N-TFAc sample showed a moderately higher GD with $18 \%$, while Cel-Asp-N-Cbz was 15\%, as can be observed in Table 1 . Those results are in fairly close agreement with the results from Elemental Analysis (subtracted from Table S1), at 21 and 17\%, respectively. These small differences between both methods (2-3\%) for quantifying the grafting degree in cellulose support the idea of using NMR spectroscopy not only for characterization but also for a rapid estimation concerning to the degree of functionalization. Besides, these results averaged 20 and $16 \%$ in Cel-Asp-N-TFAc and Cel-Asp-N-Cbz, respectively, and are in agreement with the grafting values reported for cellulose in heterogeneous modifications in comparison with the homogeneous procedures [20,38-40] as well as the regioselectivity addressed principally to C6 of AGU in esterification reactions [41]. On the other hand, the grafting degree found in the Cel-Asp samples avoids the possibility of zwitterion self-association between vicinal amino acids which could be a problem when the application of the modified cellulose requires active free zwitterionic groups.

Table 1. Percentage of cellulose modification determined by ${ }^{13} \mathrm{C}$ NMR and elemental analysis. Column 6 shows the deprotection degree (\%) in aspartic residues evaluated by ninhydrin method (details about these calculations are described in Supplementary Material by means of Table S2 and Figure S3).

\begin{tabular}{|c|c|c|c|c|c|c|c|}
\hline \multirow{2}{*}{$\begin{array}{l}\text { Modified } \\
\text { Celluloses }\end{array}$} & \multicolumn{2}{|c|}{${ }^{13} \mathrm{C}$ NMR Areas } & \multirow{2}{*}{$\begin{array}{l}\% \text { of mod. } \\
\text { by } N^{a} R^{a}\end{array}$} & \multicolumn{2}{|c|}{ Elemental Analysis } & \multirow{2}{*}{$\begin{array}{l}\text { \% of mod. } \\
\text { by } \mathrm{AE}\end{array}$} & \multirow{2}{*}{$\begin{array}{l}\% \text { of Deprotection } \\
\text { in Asp. }\end{array}$} \\
\hline & $\mathrm{C} 1$ & $\mathrm{C} \alpha$ & & $\% \mathrm{C}$ & $\% \mathrm{~N}$ & & \\
\hline Cel-Asp-N-TFAc & 58.8 & 10.4 & $18 \%$ & 39.756 & 1.402 & $21 \%$ & $13 \%$ \\
\hline Cel-Asp-N-Cbz & 52.0 & 7.7 & $15 \%$ & 44.752 & 1.398 & $17 \%$ & $0 \%$ \\
\hline
\end{tabular}

Due to the synthesis procedure for sample Cel-Asp-N-TFAc, an important cleavage of the TFAc protecting group occurred (observed in the spectrum shown in Figure 3). The ninhydrin test was applied to both samples (Cel-Asp-N-TFAc and Cel-Asp-N-Cbz) in order to determine the level of deprotection or released amino groups. The degree of deprotection was found by quantitatively determining of the free amino group in the amino acid grafted after the synthesis of both samples of cellulose. In column 6 of Table 1, it can be seen that the free amino group for Cel-Asp-N-TFAc was $13 \%$. This means, that taking in account the average of functionalization degree for this sample of $20 \%, 65 \%$ of this value was N-deprotected (Cel-Asp-N-H). This finding simplifies the two steps of reaction in one. This important conclusion is reached, from the fact that it was shown that during the synthesis process using the anhydride with N-TFAc protecting group, two reaction steps are involved: zwitterionic functionalization and $\mathrm{N}$-deprotection. A plausible explanation of this $\mathrm{N}$-deprotection can be addressed to the nucleophilic attack of the ammonia group from the $\mathrm{NH}_{4} \mathrm{OH}$ at the electrophilic carbonyl carbon to the TFAc group leaving the alpha amino group of the aspartate residue free. Similar behavior was already reported when ammonia groups are added to the double bounds of the maleic ester in cellulose [27]. In addition, this one-step procedure offers clear advantages in time and chemical consumption when it is compared with similar proposals of modifying cellulose with N-Protected amino acids [22,42].

On the other hand, sample Cel-Asp-N-Cbz did not develop the typical purple color after the addition of ninhydrin, therefore $0 \%$ is shown in Table 1 . This indicated that all of Cbz N-protecting groups remained in the aspartate graft since it was stable under the reaction conditions used [43]. 
Again, this confirms the idea that the more electrophilic carbonyl of TFAc N-protecting group, due to the inductive effect of fluorine, may be responsible for the $65 \%$ aspartate deprotection currently occurring during the synthesis. Nevertheless, some attempts focused in increasing the N-deprotection in Cel-Asp-N-TFAc were tested under different reaction conditions $\left(\mathrm{NH}_{4} \mathrm{OH}\right.$ amount, time reaction and temperature). Also, a post-reaction step was introduced where the sample was washing with $\mathrm{NH}_{4} \mathrm{OH} / \mathrm{H}_{2} \mathrm{O}$ at different ratios. However, no progress was achieved that implied higher degree of grafting or N-deprotection. On the contrary, in most of the cases, functionalization degree was the main value affected.

\subsection{Zwitterion Character in the Cel-Asp-N-H}

Since Cel-Asp-TFAc was the only sample that showed amino group deprotection in the same synthesis process, experiments conducted to evaluate the zwitterionic character $\left(-\mathrm{COO}^{-}\right.$and $\left.-\mathrm{NH}_{3}{ }^{+}\right)$ were focused exclusively on it. For this purpose, a titration curve with $\mathrm{NaOH} 0.1 \mathrm{~N}$ was performed to determine the $\mathrm{pH}$ value where the amino acid of the sample reaches its isoelectric point or the zwitterion form. Figure 5 depicts the titration curve behavior of the sample Cel-Asp-N-H at different $\mathrm{pH}$ values from 2 to 12 vs. $\mathrm{mL}$ of $\mathrm{NaOH} 0.1 \mathrm{~N}$ added. Here, isoelectric point around $\mathrm{pH} 6$ is established at middle of the $\mathrm{pH}$ values between 3 to 9 according to the $p K a$ values of the acid and amino groups of the aspartic residue, respectively. These results confirm the zwitterionic functionality conferred to this cellulose sample by means of the grafted amino acids.

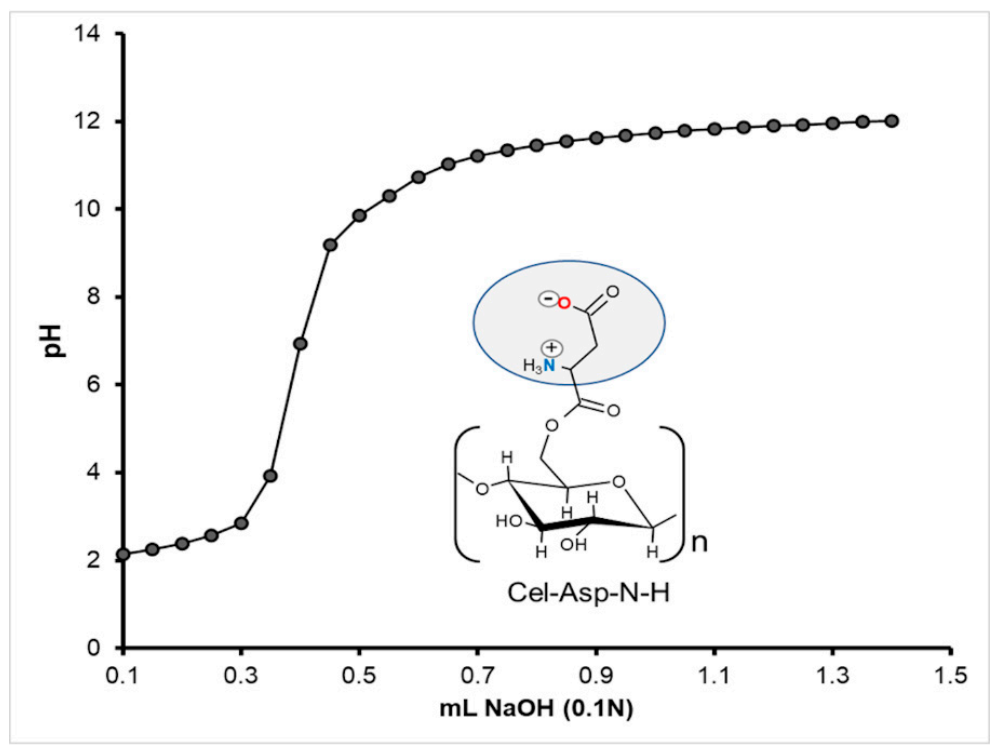

Figure 5. Titration curve of the Cel-Asp-N-deprotected.

\subsection{Availability of the Zwitterionic Moieties in Cel-Asp-N-H by a Dye Adsorption Test}

The ionic availability and activity in the zwitterionic residues of Cel-Asp-N-H sample was evaluated by means of a dye adsorption test. Cotton blue dye is a water-soluble anionic compound due to sulfonate functional groups that remain ionized above a $\mathrm{pH}$ value of 3 . According to this and the previous determined $\mathrm{pH}$ value at which isoelectric neutrality of Asp residues occurs ( $\mathrm{pH}$ 6), adsorption experiments were conducted into this range at $\mathrm{pH} 5$ which is suggested for dye adsorption in lignocellulosic materials [44]. Under this condition, cotton blue dye shows its anionic form as well as aspartic residues in cellulose present their zwitterion form. Figure 6 shows the adsorption kinetic curve of the cotton blue dye at $100 \mathrm{mg} \mathrm{L}^{-1}$ in unmodified cellulose and Cel-Asp-N-H samples up to $94 \mathrm{~h}$. The uptake ability of the materials is observed after $1 \mathrm{~h}$ of contact time. Here, the dye adsorption values are 3.5 and 3.9 milligrams per gram in cellulose and Cel-Asp-N-H (mg Dye/g Adsorbent), respectively. These close could be interpreted in the sense that the adsorption mechanism in this first step is mainly attributed to cellulose. This fact is supported by its 
known intrinsic physical and physicochemical ability to interact with dyes [45]. However, the unmodified cellulose sample reached a maximum of $40 \%(3.9 \mathrm{mg})$ of dye uptake after $96 \mathrm{~h}$ of contact time. In contrast, functionalized Cel-Asp-N-H showed an enhanced adsorption capacity of up to $70 \%$ of cotton blue dye after $24 \mathrm{~h}$, now as a consequence of the ionic interaction mechanism. Moreover, its maximum dye uptake capacity (90\%) was achieved after $48 \mathrm{~h}$. This dye uptake value remains after 72 and $96 \mathrm{~h}$ of contact time, which confirms that the maximum dye uptake value for the zwitterionic cellulose is reached at $48 \mathrm{~h}$. These results demonstrated that the zwitterionic functionalization of cellulose, in comparison with unmodified cellulose, conferred increased adsorption capacity associated either with their active ionic character as well as the availability of the grafted amino acids. Furthermore, although no separated data were obtained about the performance of the residual 35\% of Cel-Asp-N-TFAc in the zwitterionic sample, we cannot neglect the possible contribution of this N-protected sample to the dye adsorption through the coexistence of hydrogen bond interactions. On the other hand, no extensive adsorption studies were performed to this modified cellulose since the scope of the present research was focused to show a simple method to synthesized zwitterionic cellulose as well as a rapid landscape of the benefits of the modification for future applications.

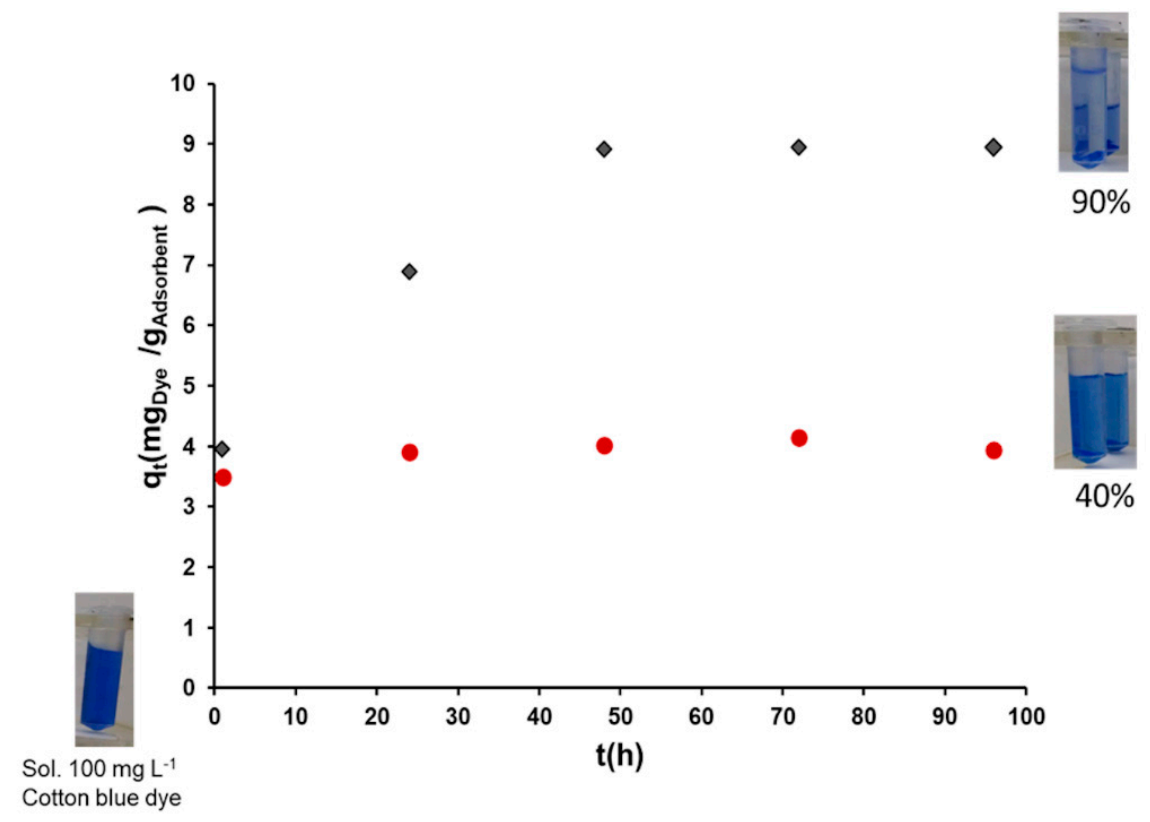

Figure 6. Cotton blue dye adsorption kinetics at $\mathrm{pH} 5$ and $30^{\circ} \mathrm{C}$ : Unmodified cellulose (red spheres) and Cel-Asp-N-deprotected (black diamonds).

In summary, the present work proved: (1) a simplified process of zwitterionic modification in renewable materials as cellulose, (2) in the same reaction conditions an important amine releasing is taking place when the aspartate anhydride is N-protected with TFAc, (3) a feasible method of modification under mild conditions and less polluted media, and (4) the presence of the ionic dual function in cellulose that could be applied to different areas such as environmental (i.e., the uptake of textile dyes or heavy metal ions in water), biotechnology (i.e., protein or enzyme immobilization), interfacial interaction (adhesives), among others.

\section{Materials and Methods}

\subsection{Materials}

Powdered spruce cellulose was used with a degree of polymerization about 560 (Fluka, Steinheim, Germany). N-Z-L-aspartic anhydride (95\%) and (s)-(-)-2-(Trifluoroacetamido) succinic anhydride (97\%) came from Sigma-Aldrich Chemie, GmbH, (Darmstadt, Germany). Ammonium hydroxide (28\% 
$\mathrm{NH}_{3}$ in $\mathrm{H}_{2} \mathrm{O}$ ) was purchased from EMScience filial of Merck KGaA, Darmstadt, Germany. Acetone ACS reagent was supplied from Sigma-Aldrich, S. de R.L. de C.V., Toluca, Mexico and cotton blue dye (C.I. 42755) was bought to Golden Bell, Mexico City, Mexico. All chemicals were used as received.

\subsection{Preparation of the Zwitterionic Celluloses from Aspartic Anhydrides}

Two separate samples of cellulose aspartate (Cel-Asp) were activated by swelling $1.0 \mathrm{~g}(6 \mathrm{mM})$ of powdered cellulose in ca. $3 \mathrm{~mL}$ of aqueous $\mathrm{NH}_{4} \mathrm{OH}(28 \%)$, with sporadic stirring, during $15 \mathrm{~min}$ at room temperature. After this period, the excess of $\mathrm{NH}_{4} \mathrm{OH}$ was removed by decantation. This treatment was repeated thrice for both samples. Then, one of the activated cellulose samples $(1.0 \mathrm{~g}$ each $)$ was reacted with $0.38 \mathrm{~g}(1.8 \mathrm{mM})$ of (s)-(-)-2-(Trifluoroacetamido) succinic anhydride (N-Trifluoroacetyl-L-aspartic anhydride) (1) dissolved in $2 \mathrm{~mL}$ of acetone. Likewise, the second activated cellulose sample (1.0 g) was reacted with $0.45 \mathrm{~g}(1.8 \mathrm{mM})$ of N-Z-L-aspartic anhydride (N-Carbobenzyloxy-L-aspartic anhydride) (2) (Figure 7) dissolved in $2 \mathrm{~mL}$ of acetone. Then both samples were stirred sporadically at room temperature during $15 \mathrm{~min}$ (when the acetone solution was fully absorbed by the cellulose). Thereafter, the mixtures were kept in a fume hood until most of the acetone evaporated, and the smell of ammonia was absent. Then, to complete the chemical modification (Figure 8), the samples were heated in an oven for $2 \mathrm{~h}$ at $60^{\circ} \mathrm{C}$. Purification of the crude cellulose aspartates from 1 (Cel-Asp-N-TFAc) and 2 (Cel-Asp-N-Cbz)) was carried out by first washing and filtering them three times with water $(5 \mathrm{~mL})$. This washing procedure was repeated in the same manner using acetone. Finally, the clean pale-yellow products were dried in an oven at $60^{\circ} \mathrm{C}$ for $4 \mathrm{~h}$.

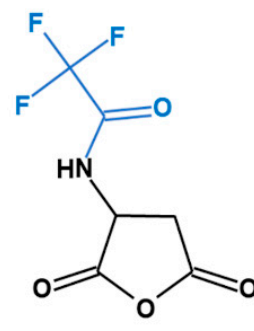

1

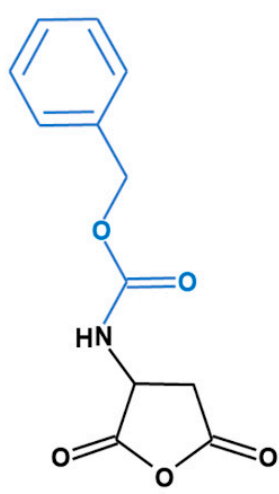

2

Figure 7. Aspartic anhydrides with N-protective group: (1) Trifluoroacetyl(TFAc) and (2) carbobenzyloxy (Cbz).

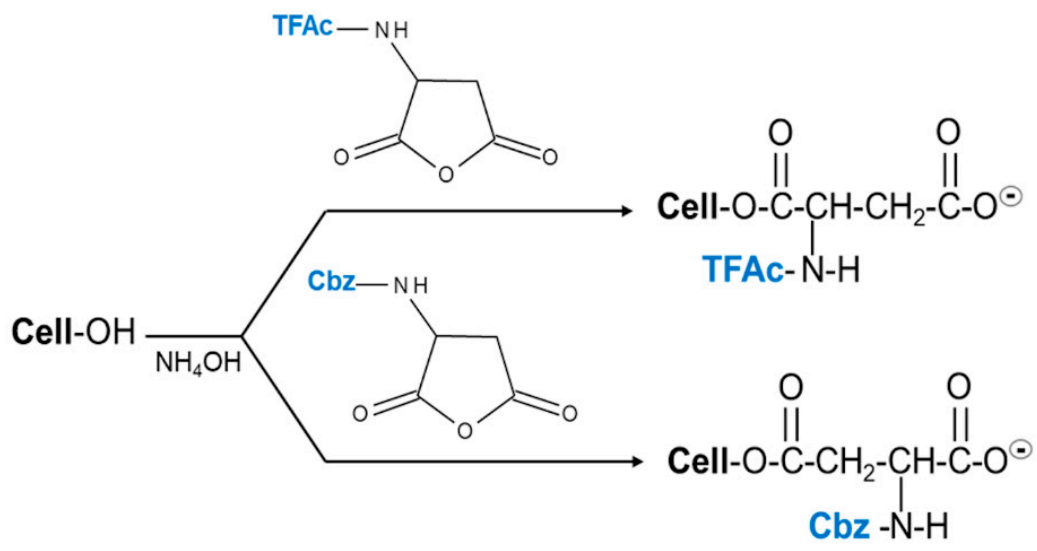

Figure 8. Schematic diagram of the syntheses of cellulose aspartate N-protected with TFAc and Cbz. 


\subsection{Characterization}

FTIR spectra were obtained by using a Nicolet iS5 Thermo Fisher Scientific FTIR spectrophotometer ( 81 Wyman Street, Waltham, MA, USA). The samples were directly measured by ATR device using 60 scans to reduce the signal/noise ratio with a $2 \mathrm{~cm}^{-1}$ of resolution.

Solid state ${ }^{13} \mathrm{C}-\mathrm{NMR}$ spectra were acquired using a 14 Tesla Jeol ECA 600 spectrometer (Tokyo, Japan) operated at room temperature, with a rotor spinning speed set to $10 \mathrm{kHz}$. Samples were packed into a $4 \mathrm{~mm}$ I.D. $\mathrm{Si}_{3} \mathrm{~N}_{4}$ rotor and measured in a two channels $(\mathrm{H}, \mathrm{X})$ solid state DOTY probe. ${ }^{13} \mathrm{C}$ CPMAS NMR experiments were used at an operation frequency of $150.9 \mathrm{MHz}$ and a $90^{\circ}$ pulse width of about $3.08 \mu \mathrm{s}$. The $\mathrm{CP}$ contact time was $3 \mathrm{~ms}$ with a $10 \mathrm{~s}$ of acquisition delay.

\subsection{Determination of the Degree of Functionalization in Celluloses}

The degree of functionalization or grafting degree (GD) in celluloses was determined quantitatively by elemental analysis (EA 1108 Fisons Instrument model EA1108 CHNS, distributed by Thermo Fisher, Waltham, MA, USA) calculating the $\mathrm{C} / \mathrm{N}$ ratio. Comparatively, solid state ${ }^{13} \mathrm{C}$ NMR was also used to estimate the functionalization [46-51]. Thus, by inspection of the ${ }^{13} \mathrm{C}-\mathrm{NMR}$ spectrum of each sample, the integral value of the signal corresponding to C1 of AGU in cellulose ( 106 ppm) [34] was used as reference. This value was compared with the integral value of the $\alpha$ carbon $(\mathrm{C} \alpha)$ signal of the N-TFAc and N-Cbz-aspartate grafts.

\subsection{Determination of the N-Deprotection Degree of the Aspartate}

The amount of $\mathrm{N}$-deprotection in the aspartate grafts in the modified celluloses was measured by using a ninhydrin method previously reported [22]. Celluloses with N-deprotected aspartates react with a ninhydrin solution developing a blue-purple color due to Schiff base formation [52]. The deprotection level in each sample was calculated by comparing the UV absorbance values at $575 \mathrm{~nm}$, with the values from a calibration curve of valine at different concentrations $(2,4,6,8$ and $10 \mathrm{mM})$.

\subsection{Zwitterion Character Evaluation}

The evaluation of the zwitterion character or the isoelectric point in the modified cellulose samples was inspected by the classical potentiometric titration method. The criterion for this evaluation is based on determining the protonation-deprotonation process preferentially in modified celluloses with free amine and acid functional groups. Briefly, a solution of $20 \mathrm{mg}$ of $\mathrm{N}$-deprotected sample in $20 \mathrm{~mL}$ of acidified water $(\mathrm{pH} 2)$ is titrated by the addition of small aliquots of $0.1 \mathrm{~mL}$ of $\mathrm{NaOH} 0.1 \mathrm{~N}$ until constant $\mathrm{pH}$ value. The titration curve was obtained by recording the $\mathrm{pH}$ values after adding each $\mathrm{NaOH}$ volume.

\subsection{Availability of the Zwitterionic Moieties by Dye Adsorption Test}

In order to evaluate the ionic contribution in the zwitterionic cellulose samples avoiding possible steric hindrance of the protecting groups in the amine, a simple adsorption test is performed only for $\mathrm{N}$-deprotected samples. A triplicated experiment of $15 \mathrm{mg}$ of modified cellulose sample in Eppendorf tubes $(2 \mathrm{~mL})$, previously treated with buffer of acetates $(\mathrm{pH} 5)$, were treated with $1.5 \mathrm{~mL}$ of a $100 \mathrm{mg} \mathrm{L}^{-1}$ solution of cotton blue dye (ionic dye), which is also buffered to $\mathrm{pH} 5$. The same treatment is applied to unmodified cellulose sample as a control. The tubes with the mixtures were constantly stirred at $100 \mathrm{rpm}$ in a laboratory incubator shaker at $30^{\circ} \mathrm{C}$. Dye adsorption capacity of the modified cellulose was determined at different contact time $(1,24,48,76$ and $96 \mathrm{~h})$. After each contact time, samples in the tubes were centrifugated at 10,000 rpm/5 min and the concentration of the residual cotton blued dye of the supernatant solution was measured at $595 \mathrm{~nm}\left(\lambda_{\max }\right)$ in a UV-Vis spectrometer Varian CARY 50CONC. 
Dye adsorbed amount per unit of adsorbent $q_{t}\left(\mathrm{mg} \mathrm{g}^{-1}\right)$ was calculated applying Equation (1):

$$
q_{t}=\frac{\left(C_{0}-C_{t}\right) V}{W}
$$

where, $C_{0}$ and $C_{t}$ are initial concentration of dye and concentration of the residual dye after time $t, \mathrm{mg} \mathrm{L}^{-1}$; $V$ is the volume of the solution, (L), and $W$ is the weight of modified cellulose used as adsorbent (g).

\section{Conclusions}

This investigation demonstrated the feasibility of synthesizing two zwitterionic celluloses Cel-Asp$\mathrm{N}-\mathrm{TFAc}$ and Cel-Asp-N-Cbz, through a simple and heterogeneous reaction procedure, using commercially available $\mathrm{N}$-protected aspartic anhydrides, employing mild aqueous conditions and a minimal use of organic solvents, namely acetone. The functionalization degree attained for cellulose functionalized with TFAc and Cbz N-protected aspartic anhydrides was 20 and 16\%, respectively. These relatively low GD values also avoid amino acid hindrance due to the association between neighboring zwitterions, which can have a positive effect for applications such as adsorbent. During the synthesis procedure, the Cel-Asp-N-TFAc sample was concurrently N-deprotected up to $65 \%$. In contrast, no purple color was developed, indicating that $\mathrm{N}-\mathrm{Cbz}$ protecting groups in $\mathrm{Cel}-\mathrm{Asp}-\mathrm{N}-\mathrm{Cbz}$, were not affected during the synthesis. These results demonstrate clear advantages based on the election of amino acid anhydrides N-protected with TFAc compared to Cbz. The zwitterionic character of the Cel-Asp-N-H (N-deprotected) sample was demonstrated by its isoelectric point at $\mathrm{pH} 6$ using a potentiometric titration method. The activity and availability of the zwitterion residues in the Cel-Asp-N-H were evaluated by means of adsorption dye test. Here, a maximum $90 \%$ of $100 \mathrm{mg} \mathrm{L}^{-1}$ of cotton blue dye solution was adsorbed in Cel-Asp-N-H after $48 \mathrm{~h}$ in comparison with the $40 \%$ shown in unmodified cellulose at the same contact time.

Finally, the synthesis procedure reported here provides important features; it: (1) is simple to perform, (2) requires minimal energy and time consumption, (3) involves a simultaneous process of zwitterionic modification of cellulose and extensive N-deprotection of the amino acid graft, (4) uses aqueous ammonia and acetone in small amounts in the reaction, implying minimal environmental risk $[10,53]$ and (5) the active zwitterionic form in the modified cellulose could be applied for several purposes, especially where the ionic interaction needs to be implied.

Supplementary Materials: The following are available online, Figure S1: ${ }^{13} \mathrm{C}$ CPMAS NMR spectrum of Cel-AspN-TFAc with integral values for each signal, Figure S2: ${ }^{13}$ C CPMAS NMR spectrum of Cel-Asp-N-Cbz with integral values for each signal, Figure S3: Calibration curve of valine at different concentrations: (1) experimental data (continuous line) and (2) calculated (dashed line). Table S1: Elemental analysis data from samples of Cel-Asp-N-TFAc and Cel-Asp-N-Cbz compared with their theoretical functionalization degrees, Table S2: Absorbance values for valine solutions with different concentrations were used for the calibration curve.

Author Contributions: Conceptualization, F.A.L.-D.T. and R.M.-G.; methodology, N.B.H.-M., J.C.M.-C. and R.M.-G.; formal analysis, R.G.-C., J.C.M.-C. and R.M.-G.; investigation, N.B.H.-M.; resources, J.A.S.-G.; writing-original draft preparation, N.B.H.-M. and R.G.-C.; writing-review and editing, F.A.L.-D.T. and R.M.-G.; visualization, J.C.M.-C., N.B.H.-M. and R.M.-G.; supervision, R.M.-G.; project administration, R.M.-G.; funding acquisition, J.A.S.-G. and R.M.-G. All authors have read and agreed to the published version of the manuscript.

Funding: This research was funded by The Nacional Council of Science and Technology (CONACyT) from Mexico under the Basic Science project CB2015, grant number 253376. CONACyT also provided the scholarship of N.B.H.-M. (grant number 366948). The APC was funded by The Department of Wood, Cellulose and Paper of the University of Guadalajara.

Acknowledgments: The authors acknowledge the Institute of Transdisciplinary Research and Services (ITRANS) of the University of Guadalajara for the NMR facilities.

Conflicts of Interest: The authors declare no conflict of interest. 


\section{References}

1. Titirici, M.-M.; White, R.J.; Brun, N.; Budarin, V.L.; Su, D.S.; del Monte, F.; Clarkd, J.H.; MacLachlang, M.J. Sustainable carbon materials. Chem. Soc. Rev. 2015, 44, 250-290. [CrossRef] [PubMed]

2. Hon, D.N.-S. Cellulose and its Derivatives: Structures, Reactions, and Medical Uses, In Polysaccharides in Medical Applications; Dumitru, S., Ed.; Marcel Dekker Inc.: New York, NY, USA, 1996; pp. 87-105.

3. Lai, Y. Chemical modification of cellulose, hemicelluloses and lignins. In Chemical Modification of Lignocellulosic Materials; Hon, D.N.-S., Ed.; Marcel Dekker Inc.: New York, NY, USA; Basel, Switzerland; Hong Kong, China, 1996; pp. 97-127.

4. Moon, R.J.; Martini, A.; Nairn, J.; Simonsenf, J.; Youngblood, J. Cellulose nanomaterials review: Structure, properties and nanocomposites. Chem. Soc. Rev. 2011, 40, 3941-3994. [CrossRef] [PubMed]

5. Heinze, T.J.; Glasser, W.G. The role of the novel solvents and solution complexes for the preparation of highly engineering cellulose derivatives. In Cellulose Derivatives: Modification, Characterization and Nanoestructures; Heinze, T.J., Glasser, W.G., Eds.; American Chemical Society: Washington, DC, USA, 1998; pp. 2-18.

6. Liebert, T. Cellulose Solvents-Remarkable History, Bright Future. In Cellulose Solvents: For Analysis, Shaping and Chemical Modification; Symposium Series; American Chemical Society: Washington, DC, USA, 2010; pp. 3-54.

7. Otto, E.; Schempp, W.; Krause, T. Production of cationic cellulose of high substitution grades in the system lithium-Chloride/dimethylacetamide. Papier 1989, 43, 694-699.

8. Song, Y.; Zhou, J.; Zhang, L.; Wu, X. Homogenous modification of cellulose with acrylamide in NaOH/urea aqueous solutions. Carbohydr. Polym. 2008, 73, 18-25. [CrossRef]

9. Anastas, P.; Eghabali, N. Green Chemistry: Principles and Practice. R. Soc. Chem. 2010, 39, 301-312. [CrossRef] [PubMed]

10. Prat, D.; Wells, A.; Hayler, J.; Sneddon, H.; McElroy, C.R.; Abou-Shehada, S.; Dunn, P.J. CHEM21 selection guide of classical- and less classical-solvents. Green Chem. 2016, 18, 288-296. [CrossRef]

11. Sousa, K.S.; Silva Filho, E.C.; Airoldi, C. Ethylenesulfide as a useful agent for incorporation into the biopolymer chitosan in a solvent-free reaction for use in cation removal. Carbohydr. Res. 2009, 344, 1716-1723. [CrossRef]

12. Knaus, S.; Bauer-Heim, B. Synthesis and properties of anionic cellulose ethers: Influence of functional groups and molecular weight on flowability of concrete. Carbohydr. Polym. 2003, 53, 383-394. [CrossRef]

13. Petroudy, S.R.D.; Syveruda, K.; Chinga-Carrasco, G.; Ghasemain, A.; Resalati, H. Effects of bagasse microfibrillated cellulose and cationic polyacrylamide on key properties of bagasse paper. Carbohydr. Polym. 2014, 99, 311-318. [CrossRef]

14. Akhlaghi, S.P.; Zaman, M.; Mohammed, N.; Brinatti, C.; Batmaz, R.; Berry, R.; Loh, W.; Tam, K.C. Synthesis of amine functionalized cellulose nanocrystals: Optimization and characterization. Carbohydr. Res. 2015, 409, 48-55. [CrossRef]

15. Salimi, H.; Aryanasab, F.; Banazadeh, A.R.; Shabanian, M.; Seidi, F. Designing syntheses of cellulose and starch derivatives with basic or cationic N-functions: Part I-cellulose derivatives. Polym. Adv. Technol. 2016, 27, 5-32. [CrossRef]

16. Araújo, A.C.; Nakhai, A.; Ruda, M.; Slättegård, R.; Gatenholm, P.; Brumer, H. A general route to xyloglucan-peptide conjugates for the activation of cellulose surfaces. Carbohydr. Res. 2012, 354, 116-120. [CrossRef] [PubMed]

17. Heinze, T.; Genco, T.; Petzold-Welcke, K.; Wondraczek, H. Synthesis and characterization of aminocellulose sulfates as novel ampholytic polymers. Cellulose 2012, 19, 1305-1313. [CrossRef]

18. Li, X.; Cao, Y.; Kang, G.; Yu, H.; Jie, X.; Yuan, Q. Surface Modification of Polyamide Nanofiltration Membrane by Grafting Zwitterionic Polymers to Improve the Antifouling Property. J. Appl. Polym. Sci. 2014, 131, 1-9. [CrossRef]

19. Zhu, Y.; Xu, X.; Brault, N.; Keefe, A.; Han, X.; Deng, Y.; Xu, J.; Yu, Q.; Jiang, S. Cellulose Paper Sensors Modified with Zwitterionic Poly(carboxybetaine) for Sensing and Detection in Complex Media. Anal. Chem. 2014, 86, 2871-2875. [CrossRef]

20. Delgado, E.; López-Dellamary, F.; Allan, G.; Andrade, A.; Contreras, H.; Regla, H.; Cresson, T. Zwitterion modification of fibres: Effect of fibre flexibility on wet strength of paper. J. Pulp Pap. Sci. 2004, 30, 141-144. 
21. Manríquez, R.; López-Dellamary, F.; Frydel, J.; Emmler, T.; Breitzke, H.; Buntkowsky, G.; Limbach, H.-H.; Shenderovich, I.G. Solid-state NMR studies of aminocarboxylic salt bridges in L-lysine modified cellulose. J. Phys. Chem. B 2009, 113, 934-940. [CrossRef]

22. Allan, G.; Delgado, E.; López-Dellamary, F. A new interfibre system for paper involving zwitterions. Pulp Pap. Fund. Res. Soc. 1983, 2, 1101-1138.

23. Laureano-Anzaldo, C.M.; Haro-Mares, N.B.; Meza-Contreras, J.C.; Robledo-Ortíz, J.R.; Manríquez-González, R. Chemical modification of cellulose with zwitterion moieties used in the uptake of red Congo dye from aqueous media. Cellulose 2019, 26, 9207-9227. [CrossRef]

24. Liu, H.; Taylor, L.S.; Edgar, K.J. The role of polymers in oral bioavailability enhancement; a review. Polymer 2015, 77, 399-415. [CrossRef]

25. Sweedman, M.C.; Tizzotti, M.J.; Schäfer, C.; Gilbert, R.G. Structure and physicochemical properties of octenyl succinic anhydride modified starches: A review. Carbohydr. Polym. 2013, 92, 905-920. [CrossRef] [PubMed]

26. Cuculo, J.A. Modifying Cellulosic Fabric with Dicarboxylic Acids to Impart Water-Dispersibility. U.S. Patent No. 3,671,184, 20 June 1972. U.S. Patent and Trademark Office, Washington, DC, USA.

27. Kretzschmar, G. Polysacharide Aspartate. European Patent No. 1065217 A1, 3 January 2001. European Patent Office, Frankfurt am Main DE, Germany.

28. Karimi, K.; Taherzadeh, M.J. A critical review on analysis in pretreatment of lignocelluloses: Degree of polymerization, adsorption/desorption, and accessibility. Bioresour. Technol. 2016, 203, 348-356. [CrossRef] [PubMed]

29. Garside, P.; Wyeth, P. Identification of cellulose fibres by FTIR spectroscopy. Stud. Conserv. 2003, 48, 269-275. [CrossRef]

30. Poletto, M.; Ornaghi Júnior, H.L.; Zattera, A.J. Native cellulose: Structure, characterization and thermal properties. Materials 2014, 7, 6105-6119. [CrossRef] [PubMed]

31. Barth, A. The infrared absorption of amino acid side chains. Prog. Biophys. Mol. Bio. 2000, 74, 141-173. [CrossRef]

32. Gonzalez-McQuire, R.; Chane-Ching, J.Y.; Vignaud, E.; Lebugle, A.; Mann, S. Synthesis and characterization of amino acid-functionalized hydroxyapatite nanorods. J. Mater. Chem. 2004, 14, 2277-2281. [CrossRef]

33. Sebben, D.; Pendleton, P. Infrared spectrum analysis of the dissociated states of simple amino acids. Spectrochim. Acta A Mol. Biomol. Spectrosc. 2014, 132, 706-712. [CrossRef]

34. Meza-Contreras, J.C.; Manríquez-González, R.; Gutiérrez-Ortega, J.A.; González-García, Y. XRD and solid state ${ }^{13} \mathrm{C}$-NMR evaluation of the crystallinity enhancement of ${ }^{13} \mathrm{C}$-labeled bacterial cellulose biosynthesized by Komagataeibacter xylinus under different stimuli: A comparative strategy of analyses. Carbohydr. Res. 2018, 461, 51-59. [CrossRef]

35. Mittal, A.; Katahira, R.; Himmel, M.E.; Johnson, D.K. Effects of alkaline or liquid-ammonia treatment on crystalline cellulose: Changes in crystalline structure and effects on enzymatic digestibility. Biotechnol. Biofuels 2011, 4, 1-16. [CrossRef]

36. Gould, J.A.; Jones, J.T.A.; Bacsa, J.; Khimyak, Y.Z.M.; Rosseinsky, J.A. A homochiral three-dimensional zinc aspartate framework that displays multiple coordination modes and geometries. RSC Chem. Comm. 2010, 46, 2793-2795. [CrossRef]

37. Sahoo, L.; Singhamahapatra, A.; Ramkumar, V.; Loganathan, D. Regioselective opening of unsymmetrical cyclic anhydrides: Synthesis of N-glycosylated isoasparagine and isoglutamine conjugates. RSC Adv. 2014, 4, 22042-22047. [CrossRef]

38. Hon, D.N.-S.; Yan, H. Cellulose Furoate. I. Synthesis in homogeneous and heterogeneous systems. J. Appl. Polym. Sci. 2001, 81, 2649-2655. [CrossRef]

39. Yoshida, Y.; Heux, L.; Isogai, A. Heterogeneous reaction between cellulose and alkyl ketene dimer under solvent-free conditions. Cellulose 2012, 19, 1667-1676. [CrossRef]

40. Junka, K.; Filpponen, I.; Johansson, L.-S.; Kontturi, E.; Rojas, O.J.; Laine, J. A method for the heterogeneous modification of nanofibrillar cellulose in aqueous media. Carbohydr. Polym. 2014, 100, 107-115. [CrossRef] [PubMed]

41. Klemm, D.O. Regiocontrol in cellulose chemistry: Principles and examples of etherification and esterification. In Cellulose Derivatives: Modification, Characterization and Nanoestructures; Heinze, T.J., Glasser, W.G., Eds.; American Chemical Society: Washington, DC, USA, 1998; pp. 19-37. 
42. Edwards, J.V.; Provost, N.T.; Condon, B.; French, A.; Wu, Q. Inmobilization of lysozyme-cellulose amide-linked conjugates in cellulose I and II cotton nanocrystalline preparations. Cellulose 2012, 19, 495-506. [CrossRef]

43. Isidro-Llobet, A.; Álvarez, M.; Albericio, F. Amino acid-protectig groups. Chem. Rev. 2009, 109, $2455-2504$. [CrossRef]

44. Drnovšek, T.; Perdih, A. Selective staining as a tool for wood fibre characterization. Dyes Pigments 2005, 67, 197-206. [CrossRef]

45. Hubbe, M.A.; Chandra, R.P.; Dogu, D.; van Velzen, S.T.J. Analytical staining of cellulosic materials: A review. BioResources 2019, 14, 7387-7464.

46. Ho, F.F.-L.; Kohler, R.R.; Ward, G.A. Determination of molar substitution and degree of substitution of hydroxypropyl cellulose by nuclear magnetic resonance spectrometry. Anal. Chem. 1972, 44, 178-181. [CrossRef]

47. Metz, G.; Ziliox, M.S.; Smith, O. Towards quantitative CP-MAS NMR. Solid State Nucl. Magn. Reson. 1996, 7, 155-160. [CrossRef]

48. Dominiak, K.; Ebeling, H.; Kunze, J.; Fink, H.-P. ${ }^{13}$ C-NMR spectroscopical investigations of the substituent distribution in cellulose xanthates. Lenzinger Ber. 2011, 89, 132-141.

49. Gaborieau, M.; Nebhani, L.; Graf, R.; Barner, L.; Barner-Kowollik, C. Accessing Quantitative Degrees of Functionalization on Solid Substrates via Solid-State NMR Spectroscopy. Macromolecules 2010, 43, 3868-3875. [CrossRef]

50. Volkert, B.; Lehmann, A.; Hettrich, K. Novel cellulose and starch-based materials. Cellul. Chem. Technol. 2014, $48,425-444$.

51. Nasatto, P.L.; Pignon, F.; Silveira, J.L.M.; Duarte, M.E.R.; Noseda, M.D.; Rinaudo, M. Methylcellulose, a cellulose derivative with original physical properties and extended applications. Polymers 2015, 7, 777-803. [CrossRef]

52. Friedman, M. Applications of the ninhydrin reaction for analysis of amino acids, peptides, and proteins to Agricultural and Biomedical Sciences. J. Agric. Food Chem. 2004, 52, 385-406. [CrossRef]

53. Sneddon, H.F. Safety first. Green Chem. 2016, 18, 5082-5085. [CrossRef]

Sample Availability: Samples of the compounds are available from the authors.

(C) 2020 by the authors. Licensee MDPI, Basel, Switzerland. This article is an open access article distributed under the terms and conditions of the Creative Commons Attribution (CC BY) license (http://creativecommons.org/licenses/by/4.0/). 